\title{
Evolution of Insect Eyes: Tales of Ancient Heritage, Deconstruction, Reconstruction, Remodeling, and Recycling
}

\author{
Elke K. Buschbeck • Markus Friedrich
}

Published online: 18 October 2008

(C) Springer Science + Business Media, LLC 2008

\begin{abstract}
The visual organs of insects are known for their impressive evolutionary conservation. Compound eyes built from ommatidia with four cone cells are now accepted to date back to the last common ancestor of insects and crustaceans. In species as different as fruit flies and tadpole shrimps, the stepwise cellular patterning steps of the early compound eye exhibit detailed similarities implying 500 million years of developmental conservation. Strikingly, there is also a cryptic diversity of insect visual organs, which gives proof to evolution's versatility in molding even the most tenacious structures into something new. We explore this fascinating aspect in regard to the structure and function of a variety of different insect eyes. This includes work on the unique compound-single-chamber combination eye of twistedwinged insects and the bizarre evolutionary trajectories of specialized larval eyes in endopterygote insects.
\end{abstract}

Keywords Evolution of development - Eye development . Visual system · Stemma - Eyelet - Strepsiptera - Tribolium . Drosophila $\cdot$ Thermonectus $\cdot$ Bolwig organ $\cdot$ Mecoptera

E. K. Buschbeck $(\bowtie)$

Department of Biological Sciences, University of Cincinnati, 614 Rieveschl Hall,

Cincinnati, OH 45221-0006, USA

e-mail: elke.buschbeck@uc.edu

M. Friedrich $(\bowtie)$

Department of Biological Sciences, Wayne State University, 5047 Gullen Mall,

Detroit, MI 48202, USA

e-mail: mf@biology.biosci.wayne.edu

\section{Friedrich}

Department of Anatomy and Cell Biology, School of Medicine,

Wayne State University,

540 East Canfield Avenue,

Detroit, MI 48201, USA

\section{Introduction}

Compound eyes represent the most prominent visual organ in the majority of insects. Pervasive taxonomic presence and high design similarity suggest that insect compound eyes represent a paradigm of evolutionary conservation. While certainly true, this is just half the story. Insects have evolved a large variety of additional visual organs that are less conspicuous and more difficult to study. As a case in point, a simple fruit fly like the extraordinarily well-studied Drosophila melanogaster uses no less than "seven eyes" (Hofbauer and Buchner 1989) (Fig. 1). Amazingly, 100 years passed after the first major publications on the optics of arthropod eyes before two of the seven visual organs were discovered (Exner 1891; Grenacher 1879). These, as will be discussed in detail, originated by segregation from the ancestral insect compound eye. The obscurity of this fact, little known even to entomology students, illustrates the mystery and also highlights an ignorance of insect eye diversity. A great deal can be learned about the evolution of animal form and function by studying insect vision, a topic that has gained new interest through the molecularly driven renaissance of comparative developmental biology (Carroll 2005). Progress in the Drosophila compound eye has precipitated surprising insights into the origins of the visual organs of other insects (Moses 2002; Trujillo-Cenoz 1985; Ready et al. 1976). Much of this review will focus on how comparative developmental biology elucidated the many ways with which evolution retooled the ancient and highly constrained design of insect compound eyes.

\section{Ocelli: Ancient Supplementary Eyes}

Two categories of Drosophila eyes are characteristic of insects in general. First, a virtually omnipresent pair of 


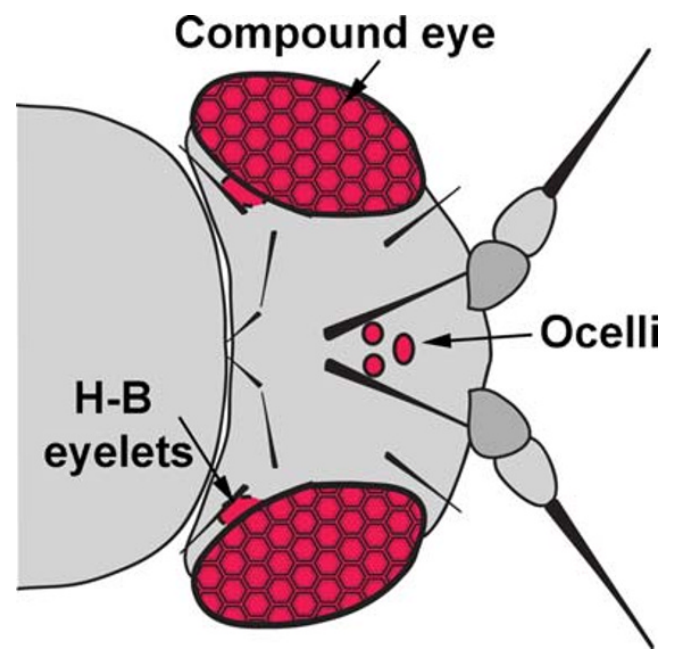

Fig. 1 The seven eyes of Drosophila consist of the two compound eyes, three ocelli and the modified Bolwig organs (H-B eyelets)

compound eyes is responsible for capturing the main share of visual information. Second, a triplet of ocelli are embedded in the dorsal head cuticle (Fig. 1) (Yoon et al. 1996). These organs tend to be underfocused singlechamber eyes, projecting a blurry image that, at least in dragon flies, is thought to detect the horizon and assist in flight control (Stange et al. 2002). Compound eyes and ocelli are present in the oldest and most primitive insect lineages such as bristletails (Archaeognatha) and jumping tails (Collembola; Fig. 2). This implies that the evolutionary events leading to their emergence and diversification preceded the origin of insects from their arthropod ancestor (Friedrich 2006a). Indeed, homologous median eyes are thought to be shared in the most closely related sister taxon to insects, the Crustacea (Fig. 2) (Paulus 1972).

Within insects, or more accurately hexapods, ocelli show limited evolutionary variation compared to the compound eyes (Goodman 1981). Surprisingly, the highest diversity of ocelli is encountered in the primitive jumping tails, some of which have been described to possess as many as six (Paulus 1972). In all of the more modern insect lineages (Ectognatha), however, only the three conventional external ocelli are found. Usually, the variability of ocelli is largely confined to presence or absence (Goodman 1981). In addition, size differences have been observed between diurnal and nocturnal species (Warrant et al. 2006). Noteworthy as well are cases of cryptic ocelli such as in sphingid moths (Lepidoptera), where they are submerged beneath the dorsal head cuticle (Dickens and Eaton 1973). Insect orders sporting conspicuous ocelli, particularly suitable for examination, include dragon flies (Odonata), grasshoppers (Orthoptera) and cockroaches (Dictyoptera) (Goodman 1981).

\section{Compound Eyes}

\section{Basic Functional Diversity}

Compound eyes are functionally analogous to single-chamber eyes that have been turned inside out. Arguably, the most important visual property of eyes is spatial resolution, which is achieved through curvature of photoreceptive tissue. A concave epithelium with pigment cells and a light-gathering lens is the basic organization of our eyes as well as the insect ocelli (Fig. 3a) (Goodman 1981). A convex epithelium, on the other hand, with pigment cells and an array of tiny lenses, is the basic organization of insect compound eyes (Fig. 3b). The latter is particularly efficient at providing large visual fields, and many insects are capable of $360^{\circ}$ vision. The level to which spatial resolution can be achieved depends on the overall size of the eye, as well as the eye's curvature (Land 1981; Land and Nilsson 2002). The latter
Fig. 2 Phylogenetic relationships and approximate ages of insect orders and other arthropod taxa explored in this review. Time line is given in million of years. Quotation marks indicate paraphyletic and potentially paraphyletic groups. Consensus topology based on (Friedrich and Tautz 1995; Kristensen 1991; Willmann 2004)

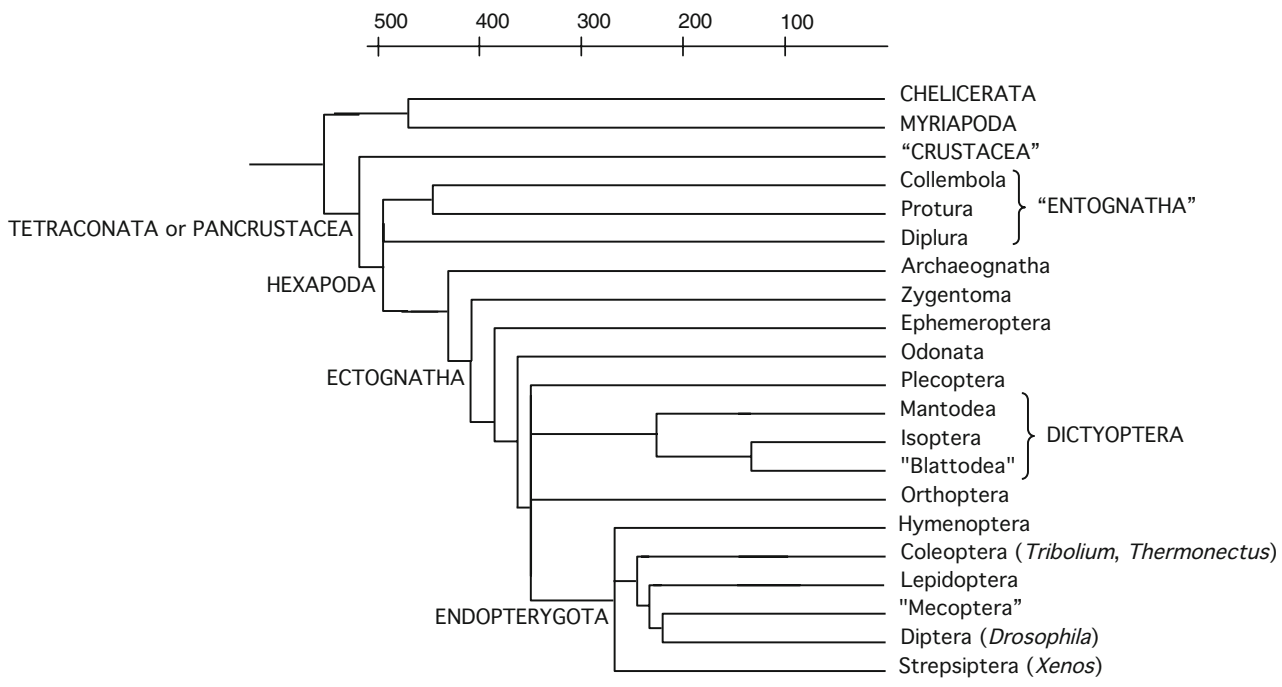




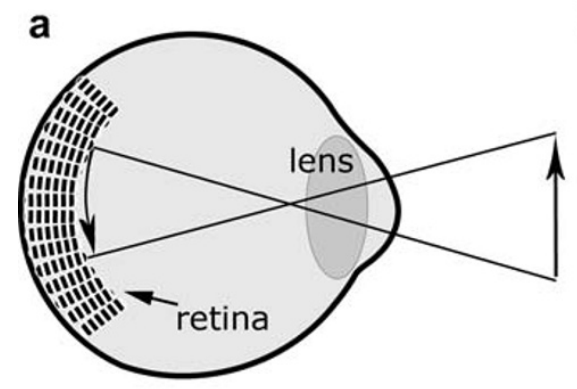

Fig. 3 Schematic of different eye types. a The single-chamber camera eye is the basic type of the human eye but also exists within insects. Spatial resolution is achieved through the lens and through a concave curvature of the retina. b Schematic of an insect compound eye.

frequently varies across different regions of individual compound eyes, including regions with heightened acuity. Insects have evolved several sub-types of compound eyes, including apposition, superposition, and neural superposition eyes. The review of these eye types is beyond the scope of this publication (but see Nilsson 1989 and Land and Nilsson 2002 for comprehensive reviews on this topic), but we will give a few examples of insect eyes that have evolved to excel in specific ways.

Among the most basal insects with particularly welldeveloped compound eyes are the dragon- and damselflies (Odonata), which are characterized by up to 30,000 ommatidia (Sherk 1978). It is no coincidence that the most elaborate compound eyes are found among the best-flying insects. Insect flight requires high spatial resolution as well as photoreceptors that are able to rapidly adjust to changes in visual scene. In addition, dragonflies are particularly good at seeing small objects. These visually guided predators are able to intercept their prey by adjusting head positions to maintain their victim in an area of the eye with particularly high acuity (Olberg et al. 2007). Among the more basal insects, another group of interest is the praying mantis (Mantodea). While they do not perform aerial pursuits, their high-acuity vision allows them to accurately gage the distance to their prey (Kral 1998). In addition to other methods of distance estimation, they are able to detect minor differences between the image of the right and left eye to correctly estimate the distance of their prey. This has been elegantly demonstrated through the placement of prisms in front of their eyes, leading to enhanced or reduced disparities of the two images: Accordingly, the praying mantises undershoot or overshoot their prey (Rossel 1983).

While high acuity is important, other visual modalities have been highly adaptive throughout insect evolution. Among them is the ability to detect the direction of the electric field component (e-vector) of linearly polarized light (see Wehner and Labhart 2006 and Horváth and Varjú 2004 for recent reviews). This ability can be used for orientation

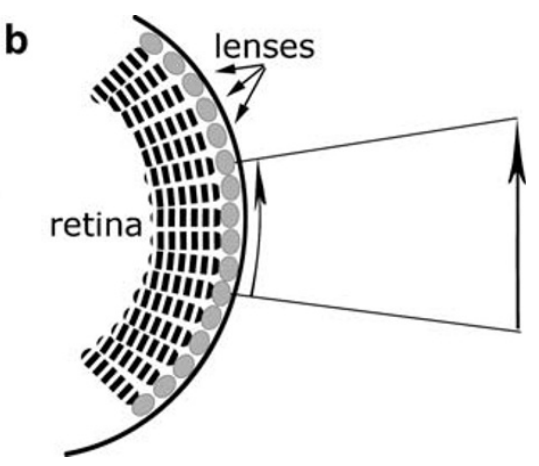

Spatial resolution is achieved through a series of small lenses and a convexly shaped retina. Striped areas indicate regions of photoreception, which in real eyes tend to be separated by screening pigment

(Wehner 1992; von Frisch 1967), the detection of water surfaces (Horvath and Varju 1997; Schwind 1991), and in communication (Cronin et al. 2003; Marshall et al. 1999). A specialized region for polarized vision exists in the dorsal rim area of most compound eyes. The dorsal rim area hence represents an ancient component of the insect retina, having been described in species ranging from dragonflies to Diptera (see Labhart and Meyer 1999).

Color vision is another specialty enabled by restricting incoming light (see Kelber 2006). Multiple photoreceptor cells, each sampling a different portion of the spectrum, are compared to facilitate the discrimination of color. The ability of honeybees (Hymenoptera) to differentiate between colors was already observed by Karl von Frisch early in the twentieth century (von Frisch 1914). Indeed many insects are thought to possess color vision (Briscoe and Chittka 2001), an ability that requires bright light because each receptor samples a relatively narrow visual spectrum. However, it has recently been demonstrated that the nocturnal hawkmoth Deilephila elpenor (Lepidoptera) is able to discriminate colors at light levels as low as dim starlight (Kelber et al. 2002). While this ability may be exceptional, the eyes of many other insects are able to detect contrast at low light levels. Generally, this requires substantial pooling and therefore tends to result in somewhat reduced spatial resolution (see Warrant 2006 for review). A particularly interesting example are the nocturnal halictid bees, which use visual landmarks to find their nest (Warrant et al. 2004). In these species, light capture is thought to be facilitated by relatively large rhabdoms (the site of photodetection) and through spatial pooling at the neurological level (Greiner et al. 2004). Drastically enlarged rhabdoms also are found in nocturnal ants (Greiner et al. 2007).

\section{Ancient Heritage}

Regardless of adaptive fine-tuning, insect compound eyes are formed from ommatidia, each of which represents a 
functional unit that is composed of a highly conserved set of cells. A single ommatidium includes two corneagenous or primary pigment cells, four crystalline cone cells and a set of usually eight photoreceptor (retinula) cells (Paulus 2000) (Fig. 4). The latter are characterized by one or more areas of dense microvilli, referred to as rhabdomeres. Frequently, several rhabdomeres are at close physical proximity, forming rhabdoms. These contain opsins, which are molecules that facilitate the generation of electrical signals in response to light absorption. Evidence that this cellular architecture has long provided spatial orientation and color discrimination has been supported by insect orders with well-developed compound eyes represented by deposits from the Devionian (Fayers and Trewin 2005). This leads to the conclusion that the basic insect compound eye has been conserved for at least 360 million years (Fig. 2). Surveying even more distantly related species leads to the inference that the compound eye may be considerably older. This is clearly suggested by the widespread presence of compound eyes in crustacean species, many of which include highly detailed blueprints of insect-like compound eyes (Paulus 1979; Melzer et al. 1997). There has been considerable discussion of whether these similarities could have been the consequence of independent evolution or shared evolutionary ancestry (Osorio and Bacon 1994). Several lines of evidence now suggest that the latter is the case. An overwhelming number of studies show that crustaceans are more closely related to insects than to the other two arthropod groups, myriapods and chelicerates (Fig. 2) (Regier et al. 2005; Friedrich and
Tautz 1995; Hwang et al. 2001; Strausfeld 1998). Some myriapod and chelicerate species carry compound eyes as well, but these exhibit less similarity than is observed between insects and crustaceans (Harzsch et al. 2007; Harzsch et al. 2006). Informatively, of the two synonyms for the super-clade constituting crustaceans and insects, Pancrustacea and Tetraconata, the latter refers to the presence of four cone cells in the ommatidia of insect and crustacean species (Shultz and Regier 2000; Dohle 2001). Next, there are also detailed anatomical similarities of optic brain compartments, which render the possibility of independent evolution of insect and crustacean compound eyes very unlikely (Osorio and Bacon 1994; Strausfeld 1998; Sinakevitch et al. 2003; Strausfeld 2005). In both systems, visual information is processed retinotopically, meaning that neighboring visual information is processed in topographically neighboring brain areas. Thus, the conservation of the insect compound eye has also manifested in the conserved organization of the optic brain. This consists of three or four subunits: the lamina, the medulla, and lobula complex, the latter of which sometimes is divided into a lobula and lobula plate (Fischbach and Dittrich 1989; Strausfeld 1976). Particularly well-conserved are the lamina and lobula plate, which exist even in brine shrimp (Crustacea, Entomostraca, Branchiopoda), in which a medulla is absent (Strausfeld 2005). Even more similar to insects are the optic lobes of crayfish (Crustacea, Malacostraca), which are characterized by the presence of a medulla and separate lobula and lobula plate, as well as major similarities in the architecture of chiasmata. Possibly, the largest difference

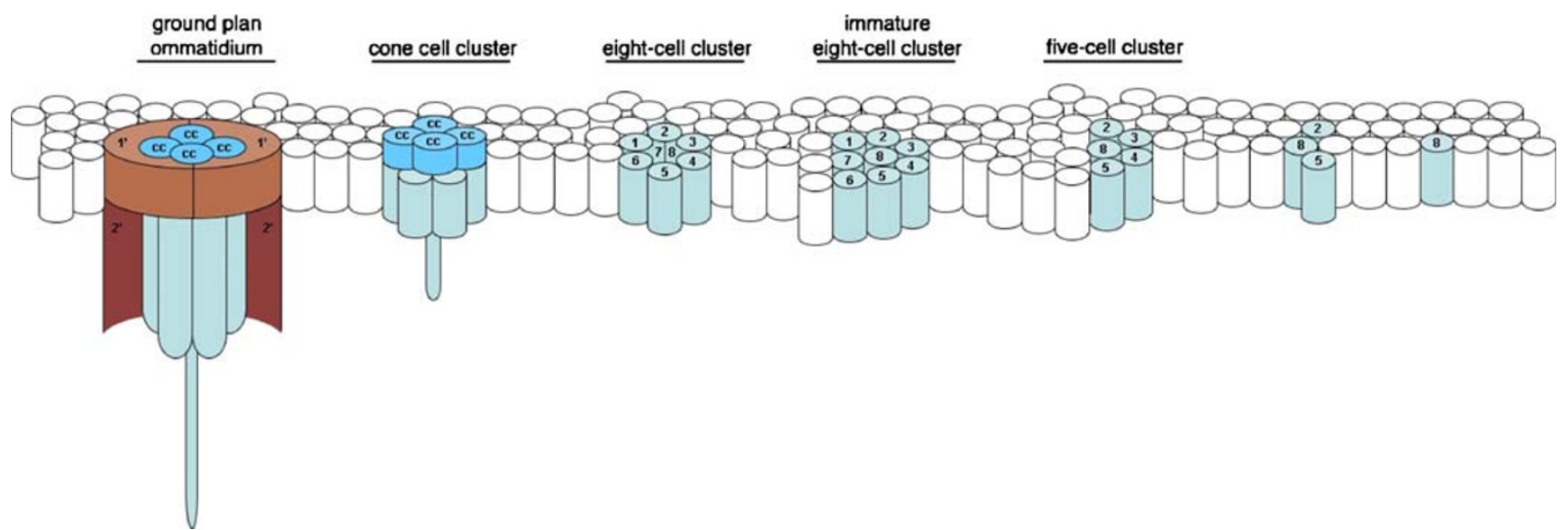

Fig. 4 Ground plan and development of the insect ommatidium. Lateral view of a cross-section along the differentiating retina epithelium. In the differentiating retina of Drosophila and other insects, the cellular components of each ommatidium assemble in a highly regulated sequence, which is shown here increasing in cellular organization from right to left in the wake of an inductive differentiation front that moves in anterior direction (right). The first cell fates to be established are those of photoreceptors 1-8. Subsequently, cone cells (cc) are specified from peripheral cells and move with their main cell body on top of the photoreceptor-cell assembly (cone cell cluster). Further accessory cell types including the pair of primary pigment or corneageneous cells $\left(1^{\prime}\right)$ join during terminal differentiation of the ommatidium. Labeled ommatidial cluster stages, as well as the labeled components of the differentiated ommatidium, are conserved between insects and crustaceans as demonstrated by studies in Drosophila and the tadpole shrimp Triops cancriformis (Crustacea, Notostraca) (Melzer et al. 2000) 
between insects and malocostracean optic lobes is the presence of a separated inner medulla in insects. Other differences between the neuropils of crustacean and insects include details in the layering of the medulla. Regardless, the overwhelming number of similarities between insect and crustacean optic brains is suggestive of ancient origin of central nervous system components of the insect visual system (Strausfeld 1998; Sinakevitch et al. 2003; Harzsch 2002).

Last but not least, there are striking parities between the earliest steps of retinal development in crustaceans and insects. As first described in Drosophila, the differentiation of the compound eye proceeds through a carefully choreographed sequence of ommatidial patterning steps (for review see Wolff and Ready 1993; Morante et al. 2007). This process starts with the specification of eight photoreceptor cells, followed by cone cells, primary pigments cells and further accessory cells (Fig. 4). Remarkably, the differentiating retina of crayfish (Crustacea, Malacostraca) and tadpole shrimps (Crustacea, Anacostraca) share many of the ommatidial patterning stages (Melzer et al. 2000; Hafner and Tokarski 1998). This implies that the retinal patterning of the ancestor to insects and crustaceans has remained conserved for more than 500 million years (Walossek and Muller 1990). This conclusion is further supported by the similar retinal patterning in grasshoppers (Orthoptera), moths (Lepidoptera), and beetles (Coleoptera) (Egelhaaf 1988; Friedrich et al. 1996; Champlin and Truman 1998; Friedrich and Benzer 2000). Seemingly, the differentiation of the insect compound eye is one of the most conserved cellular patterning processes known.

\section{Reduction and Deconstruction}

Considering the enormous time range through which the structure and design of the compound eye remained conserved in the Pancrustacea (a.k.a. the Tetraconata; Fig. 2), one may wonder which, if any, factors may have imposed modification. Nonetheless, the body of comparative research on compound-eye structure is considerable (Nilsson 1989; Oakley 2003; Meinertzhagen 1991; Bitsch and Bitsch 2005; Land 1991; Land et al. 1999). After all, with at least 750,000 species, insects were given many opportunities for "evolutionary tinkering" (Jacob 1977). Most variations in the insect retina represent slight reductions, or expansions, in number of photoreceptor cells per ommatidium, while cone cells appear to be virtually numerically invariant (for review see Oakley 2003). An interesting example is the addition of a ninth photoreceptor, which occurred independently in Hymenoptera and Lepidoptera (Fig. 2) (Friedrich et al. 2006). In the Lepidoptera especially, there are species with higher and more variable numbers of photoreceptors per ommatidium (Egelhaaf 1988).
Another type of variation relates to eye size as measured in dimensions or number of ommatidia. The largest known insect eyes belong to the previously mentioned dragon flies (Odonata) (30,000; Sherk 1978). Interestingly, compoundeye reduction has not yet been systematically explored, although reduction may well relate to the considerable energetic costs therein. In Drosophila, it has been estimated that the ATP used to maintain electric currents of illuminated photoreceptor cells accounts for $8 \%$ of the total energy that is consumed at rest (Laughlin et al. 1998). Note that these calculations do not account for any costs arising from the constant renewal of the photoactive membrane, the maintenance of support cells, or the neural activity needed to process the visual information (Laughlin 2001). However this represents an arbitrary sample. A comprehensive treatment of this topic may reveal ecological correlations to eye reduction. Considering paleontological and phylogenetic data, insects contain examples of both very ancient as well as comparatively recent eye reduction. In the former case, jumping tails (Collembola) are known for their reduced lateral eyes, which consist of few but complete ommatidia (Kristensen 1991). Other ancient hexapods with similarly or even more extremely reduced eyes are the Protura and Diplura (Conde and Pages 1991; Imadate 1991). Importantly, because elaborate compound eyes are conserved in the Crustacea, one can conclude that these basal insect orders underwent reduction of an initially more complete compound eye. Moreover, not all primitively wingless insects experienced compound-eye reduction, as the large lateral eyes of bristle tails (Archaeognatha) indicate (Watson and Smith 1991).

It is possible to infer recent reduction if eye-reduced species are closely related to those with eyes of average size. Such examples are found among contributors to the faunas of light-deprived environments like crevices, karsts, and caves. Facultative cave inhabitants (troglophilic) with reduced eyes and obligatory cave species (troglobitic) that are completely eyeless are found in Orthoptera, Coleoptera, and Diptera (Harvey et al. 2000). Some species with highly reduced eyes are much closer to our homes, e.g., the harmless silverfish (Zygentoma) (Smith and Watson 1991). More harmful, but increasingly more popular as a model system for development and insect genomics, is the starch-consuming darkling beetle species Tribolium castaneum (red flour beetle) (Klingler 2004). In this case, the compound eye is only $\sim 90$ ommatidia large, in contrast to closely related darkling beetles, which possess hundreds of ommatidia per compound eye.

Remodeling of Compound Eyes in Twisted Wing Insects (Strepsiptera)

One possible example of reduction with consecutive elaboration is the eye of twisted wing insects (Strepsiptera). 
This group has evolved dramatically remodeled eyes that substantially differ in function from those of other insect orders. While compound eyes generally tend to resolve one image point per lens, the eyes of Strepsiptera are among very few exceptions (Land and Nilsson 2002). This insect order represents a particularly enigmatic group, often known to systematists for their unclear position (Fig. 2) (see Beutel and Pohl 2006 for recent review), and whose unusual eye organization has long been noted (MacCarthy 1991; Rösch 1913). In fact, the eye organization is so peculiar that it has led Mike Land to comment: "One is tempted to conclude that these eyes, so unlike anything in any other insect, either came from outer space or were put here by God to confuse scientists" (Land 1984).

Functionally, the strepsipteran eye represents a hybrid of image-forming eyes and canonical compound eyes (Buschbeck et al. 1999; Buschbeck et al. 2003). While typical compound eyes gain spatial resolution exclusively through their convex surface (Fig. 3b), the strepsipteran eye is composed of small, concave-image-forming units, called eyelets (Fig. 5). Externally, Strepsiptera differ by presenting far fewer but much larger lenses (Kinzelbach 1971). In the Strepsiptera, Xenos peckii, for example, there are only about 50 lenses, much fewer than the over 700 facets of the slightly smaller fruit fly $D$. melanogaster. Moreover, a typical lens in $X$. peckii is about $65 \mu \mathrm{m}$ in diameter and covers about the same area as do 15 fruit fly lenses (Buschbeck et al. 1999). Typical insect compound eyes possess only eight to ten photoreceptor cells per facet. In contrast, beneath each Strepsiptera lens lies a small, cupshaped retina, which, in $X$. peckii, is comprised of over 100 photoreceptor cells. Each lens and retina together, therefore, forms a small single-chamber eye that resolves only a partial image, namely that of the small portion of the visual field that lies above it. The collective resolution of each of these eyelets is limited. Based on anatomical findings (Buschbeck et al. 2003) and on behavioral studies (Maksimovic et al. 2007), it is only around 13 points. However, in function, the

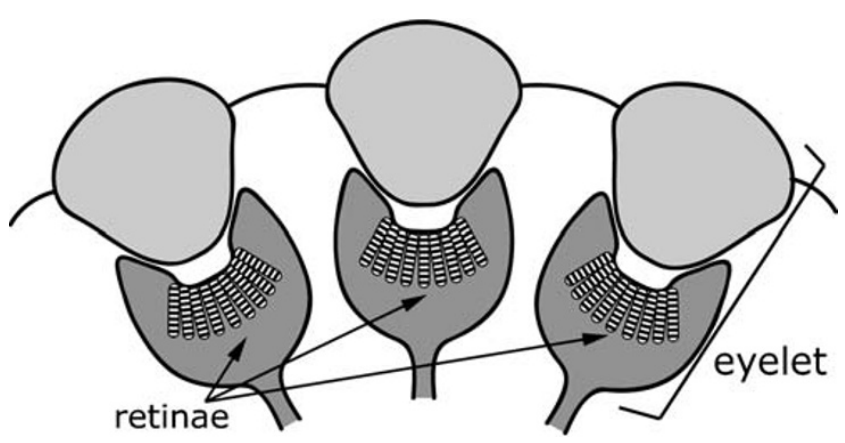

Fig. 5 The strepsipteran eye represents a combination of a compound eye and image-forming lens eyes. It consists of eyelets, each of which resolves a small portion of the visual field of the insect increase in total resolution is substantial, from about 50 to 650. This resolution seems to assist in the one task that a male Strepsiptera needs to accomplish in the few hours of his very short life: finding a female to mate.

While strepsipteran eyes neither "came from outer space," nor "were put here by God to confuse scientists," their evolutionary origin still remains somewhat unclear. This is largely due to major uncertainties in the systematic placement of Strepsiptera, as well as limited availability of especially the most basal strepsipteran groups. Nevertheless, there is evidence for the evolution of this eye from a more typical insect compound eye. Most of the systematic debate centers around where within holometabolous insects Strepsiptera fit best (Fig. 2) (Kristensen 1999; Hwang et al. 1998; Bonneton et al. 2006), implying that their ancestors undoubtedly had compound eyes. Furthermore, at least at the level of gross morphological development, many parallels with typical insect compound eyes have been observed. These include the presence of separate larval eyes that degenerate and shift during development (Buschbeck 2005).

One ontogenic possibility is that as a first step, the ancestral compound eye was largely reduced, possibly due to adopting a nocturnal lifestyle. While little is known about the eyes of the most ancestral strepsipteran groups, the most ancestral living group of Strepsiptera, the Mengenillidae, is indeed nocturnal (Pohl 2002). A nocturnal history is also supported by the fact that strepsipteran eyelets resemble the ommatidia of some nocturnal insects, such as certain mosquitoes (Land et al. 1999). Several eyelet characteristics are consistent with vision at low light levels. These include large lenses, short rhabdoms, slow receptor-cell physiology, and possibly the absence of color vision (Buschbeck et al. 2003). If strepsipteran eyes first evolved to accommodate low-light vision, then additional photoreceptors in each unit could have evolved to enhance the light capture of individual sample points. Concomitantly, the total number of lenses could have been reduced to enhance light capture at the cost of spatial resolution. If a secondary shift in lifestyle resulted in X. peckii's ancestors becoming diurnal again (which indeed they are), then the abundance of receptor cells within each unit could have led to a secondary increase of visual resolution within each eyelet.

At this point, it remains unclear if this truly is how strepsipteran eyes evolved, and many questions remain. For example, how did additional photoreceptors appear in each unit, considering that facets are so rigidly conserved in other insect taxa? Several possibilities await further investigation. These include the fusion of ancestrally separate ommatidia, as has been suggested for diplopods and chilopods (Harzsch et al. 2007), or the independent evolution of a large amount of additional receptor cells similar to some crepuscular Lepidoptera (Egelhaaf 1988). 


\section{The Larval Eyes}

Returning to the seven eyes of Drosophila, two eyes still await to be introduced. These are the so-called HofbauerBuchner (H-B) eyelets, small photoreceptor bundles deep in the optic brain of the fly (Fig. 1) (Hofbauer and Buchner 1989; Yasuyama and Meinertzhagen 1999). The Drosophila H-B eyelets do not qualify as eyes in the strict sense of image-forming devices. However, they are without doubt visual organs based on connectivity and the expression of photoreceptor specific proteins such as opsins (Malpel et al. 2002). This leads to questions such as where the H-B-eyelets may have come from and what their function is. The answers are hidden deep inside the larvae of Drosophila, which use specialized larval eyes, called stemmata.

\section{Scorpion Flies and the Origin of Insect Larval Eyes}

Stemmata are larval eyes found specifically in indirectly developing insects (Endopterygota or Holometabola) like butterflies, honeybees, and Drosophila, and which undergo dramatic changes during postembryonic development (Kristensen 1999; Friedrich 2003). In endopterygote insects, the egg releases a juvenile instar, the larva, whose physique has little in common with the adult (see Fig. 6 for correlated diversity of larval head morphologies). One corollary of this is the lack of compound eyes and the use of specialized larval eyes. From what did these larval eyes evolve? In many species, the larval eyes lack any similarity to the adult compound eye. However, in representatives of the order scorpion flies (Mecoptera), which are quite closely related to the true flies (Diptera), the larvae are equipped with small compound eyes composed of ommatidia (Fig. 6b) (Steiner 1930). One may therefore ask what then defines these as specialized larval eyes? It is the fact that, as in other endopterygote insects, they are replaced by the adult compound eyes during pupation (Paulus 1989). Hence, the mecopteran larval eyes are specialized larval eyes based on their life-history stage restriction. This is a definitive difference to directly developing insects, where the first juvenile instar is born with true compound eyes that are carried over into the adult stage (Fig. 6a). There is a second, less obvious difference as well. Juvenile compound eyes continue to expand during postembryonic development by the addition of new ommatidia in directly developing species (for review see Friedrich 2006b), in contrast to the compound eyes of mecopteran larvae which do not further increase in size (Paulus 1989).

The conservation of compound-eye-like larval eyes in scorpion flies was critical for relating the postembryonic visual development of directly developing and endopterygote species. As the comparative entomologist Hannes Paulus pointed out, the scorpion fly larval eyes represent living proof that insect larval eyes evolved from a compound-eye-like precursor organ (Paulus 1986). Comparative developmental biology has since shed additional light on the evolutionary origin of the larval eye (Friedrich 2006b). Through the use of molecular markers, for instance, it was confirmed that the embryonic localization of the differentiating larval eyes of endopterygote insects corresponds to the developing embryonic compound eye in directly developing species (Fig. 7) (Liu and Friedrich 2004). From these findings, one can conclude the larval eyes of endopterygote insects are homologous to the compound eyes of the first instars of directly developing species (nymphs). Second, the adult eyes of endopterygote species correspond specifically to the portion of the adult eye that is added on during postembryonic development in directly developing insects (Fig. 7). Hence, insect larval eyes originated by the separation of the embryonic and postembryonic partitions of the compound eye in the last directly developing ancestor of endopterygote insects.

\section{Evolutionary History of the Drosophila Larval Eyes}

Insect larval eyes experienced numerous modifications in the highly diversified lineages of endopterygote insect orders (Gilbert 1994). One of the most dramatic changes occurred in the higher Diptera, specifically in the lineage leading to Drosophila (Melzer and Paulus 1989). The Drosophila larva performs light-oriented behavior using a pair of photoreceptor bundles that attach to each side of the cephalopharyngeal head skeleton of the maggot and constitute the Bolwig's organs (BO; Fig. 6d) (Busto et al. 1999). Originally discovered by Niels Bolwig in the closely related house fly (Bolwig 1946), the BOs had at first not been related to the compound eye. However, comparative analysis in a wide range of Diptera established that even these enigmatic visual organs are related to ommatidia-like precursor structures (Melzer and Paulus 1989). Consistent with this, it has been found that the genetic control of photoreceptor-specific opsin expression in the $\mathrm{BO}$ is almost identical to the ommatidia of the adult eye (Friedrich in press). In addition, there are many detailed parallels in the participation of genes during the induction and specification of different cell fates in the two visual organs (Friedrich 2006b). At this point, over ten shared regulators of early patterning have been identified (Friedrich in press, 2006a).

Is it possible to reconstruct the steps that lead from the neat arrangement of ommatidia in the ancestral larval eye to the bare-bone BO of the Drosophila larva? An obvious difference is the complete absence of accessory cells in the BO. This implies a reduction in pigment and cone cells. The actual evolutionary process leading to this "stripdown" becomes easy to conjecture if one recalls the sequence of cell fate determination steps during normal 
Fig. 6 A snapshot of juvenile eye diversity in insects. a Nymphal compound eye in the first instar nymph of a grasshopper illustrating a typical compound eye. b Head of mecopteran larva, which has a compound-eye-like eye. Modified after (Steiner 1930). c Larval stemmata of the red flour beetle $T$. castaneum. d Bolwig organs of the Drosophila larva. Modified after (Melzer and Paulus 1989)

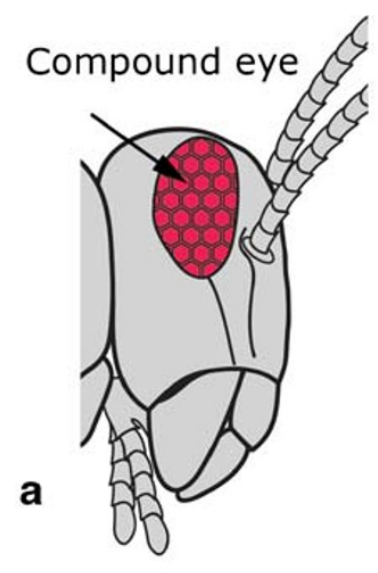

Stemmata forming a compound eye

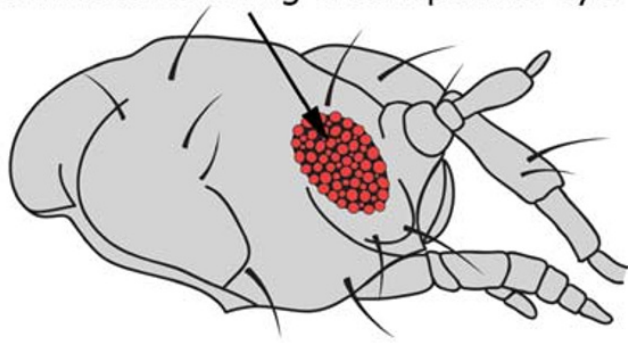

b

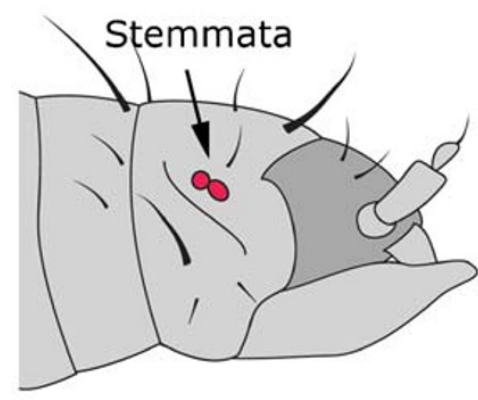

C

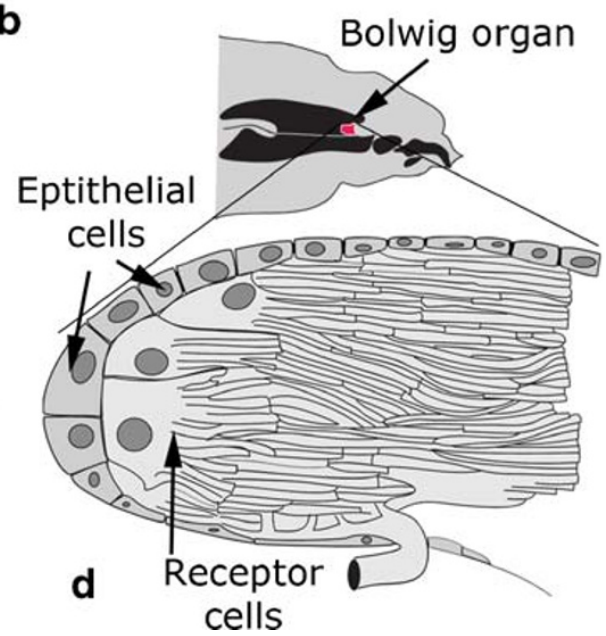

ommatidial development (Fig. 8). This is because the pigment and cone cell fates are established subsequent to the photoreceptor-cell fates (Ready et al. 1976; Wolff and Ready 1993). The evolutionary loss of accessory cells in the $\mathrm{BO}$ is therefore simply explained by precocious abrogation of ommatidial differentiation (Fig. 8).

The deconstruction of the ommatidial ground plan goes even one step further. Five photoreceptor sub-types exist in the Drosophila adult eye, which are distinguished by the differential expression of opsin genes (for review see Cook and Desplan 2001). The central R8 photoreceptor is the first cell to differentiate (for review see Morante et al. 2007, Freeman 1997). Since the specification of all subsequent photoreceptor-cell fates is dependent on its presence, the R8 photoreceptor is therefore also referred to as the founder cell (Dokucu et al. 1996). A second central photoreceptor, the R7 cell, is the last photoreceptor cell to differentiate. In Drosophila, the R7 photoreceptors are also unique in expressing UV-sensitive opsin genes (Montell et al. 1987). The remaining six peripheral photoreceptors express longwavelength-sensitive opsins. In the BO, there are only two photoreceptor sub-types (Figs. 6d and 8) (Sprecher et al. 2007). Three to four photoreceptors express a blue-sensitive opsin and differentiate first. These photoreceptors represent homologs of R8 founder cells in the adult eye (Friedrich in press). The second group is comprised of ten to 16 long- wavelength opsin-expressing cells that correspond to the peripheral photoreceptors of the adult eye ommatidia. The BO therefore lacks a UV-sensitive photoreceptor. This suggests that the R7 photoreceptor was lost during the evolution of the Drosophila larval eyes (Friedrich 2008). Strikingly, similar to the case of the accessory cells, the R7 photoreceptor is the last photoreceptor cell to differentiate during ommatidial development (Fig. 8). It thus is the first photoreceptor cell poised for disappearance by early termination of the ommatidial cell fate specification sequence.

\section{Recapitulated Fusion of Ancestral Ommatidal Units} in the Larval Eye of Flour Beetle

The presence of more than four founder cell in the BO represents another interesting difference between it and the adult ommatidia (Fig. 8). It suggests that the BOs originated by the ancestral fusion of three to four ommatidia. Intriguingly, the integration of ancestral ommatidia to larger larval eyes was hypothesized earlier (Paulus 1986). This proposal was based on the observation that the larval eyes of many insects consist of a loose assemblage of a few isolated but largely completely organized ommatidia. Developmental data from the red flour beetle T. castaneum provide further support for this scenario. The Tribolium larva is equipped with a normal head capsule that sports 

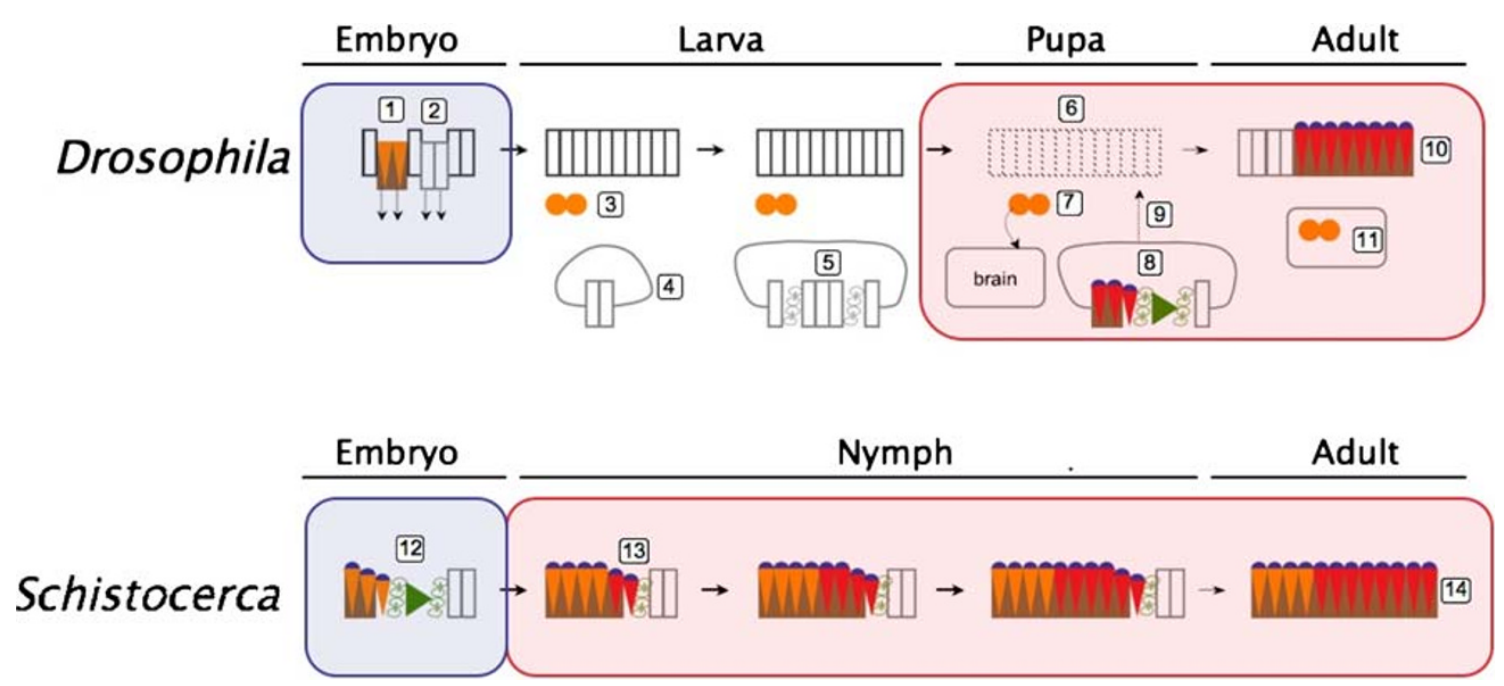

Fig. 7 Homology of eyes in directly developing and endopterygote insects (after Friedrich 2006b). a Indirect development shown in $D$. melanogaster. 1 Differentiation of larval eyes (Bolwig organs). 2 Specification and separation of eye-antennal imaginal disc cells. 3 Functional Bolwig organs. 4 Nascent eye-antennal imaginal disc. 5 Cell proliferation in eye-antennal imaginal disc during larval development. 6 Degradation of larval epithelium. 7 Dedifferentiation of the Bolwig organs to H-B eyelets by relocalization into the brain. 8 Onset of retinal differentiation in the eye-antennal imaginal disc. 9

lateral stemmata as larval eyes (Fig 6c) (Liu and Friedrich 2004). If examined closely, two discrete photoreceptor groups can be seen on each side of the head, which are referred to as dorsal and ventral stemmata (Fig. 6c). Investigation of their differentiation in the embryo, however, revealed the initial formation of five discrete photoreceptor clusters (Liu and Friedrich 2004). During late embryonic development, two of the initial clusters fuse to form the dorsal stemma. In parallel, three ventral clusters merge to form the ventral stemma. From an evolutionary perspective, the morphogenesis of the Tribolium larval eyes appears to recapitulate the postulated fusion of ancestral ommatidia.

The Tribolium larval eyes further document that cellular reduction is a pervasive theme in the evolution of insect larval eyes. Like the Drosophila BOs, the Tribolium larval eyes lack cone and pigment cells, implying a reduction of all accessory cells. The direction of light flux is influenced by the heavy pigmentation of the photoreceptors themselves, which force light to enter from a limited angle. Since species with primitive ommatidium-type larval eyes are known in both Coleoptera and Diptera (Gilbert 1994), one has to conclude that the reduction of accessory cells occurred independently in the lineages leading to Drosophila and Tribolium. It is noteworthy that in both of these groups, the ecology of larvae appears to render vision less important (Busto et al. 1999; Park 1934). The reduction may therefore be the result of evolution against costly visual organs.
Eversion of eye-antennal imaginal disc. 10 Functional Drosophila compound eye generated by fully everted and differentiated eyeantennal imaginal disc. 11 Drosophila H-B eyelets. b Direct development shown in the American desert locust Schistocerca americana. 12 Onset of retinal differentiation in the embryo. 13 Postembryonic expansion of the nymphal compound eye. 14 Adult grasshopper compound eye. The embryonic phase of eye development is indicated by blue background. The postembryonic phase of eye development is indicated by red background

\section{Remodeling of Larval Eyes}

It would be misleading to conclude from Tribolium and Drosophila that the larval eyes of endopterygote insects faced only two possible evolutionary fates: conservation or deconstruction. The evolution of the insect visual system has been far more versatile. Despite only inheriting a tiny fraction of the adult compound eye, not all larvae of holometabolous insects have poor vision. In fact, there are several examples of larvae with quite good vision. Among them are certain Nematocera (the more basal flies) such as mosquitoes, which achieve improved vision simply by expressing the adult compound eye early (Gilbert 1994) (Fig. 9a). This accelerated development of the adult eye serves both the larvae and the pupa, which is extraordinarily mobile and efficient at predator avoidance.

Several holometabolous insect larvae were able to inhabit unique habitats, presumably in part by evolving good eyes. Among them are predatory species that, relieved of the need for adult-specific visual functions (such as mate detection), evolved eyes specialized for prey capture. The most sophisticated stemmata have evolved in different groups of Coleoptera: tiger beetles (Cicindelidae) and diving beetles (Dytiscidae).

The best-studied larval visual system is that of the tiger beetle, Cicindela chinensis. This consists of six stemmata on each side, two of which are particularly sophisticated imageforming lens eyes with extended cup-shaped retinas (Fig. 9b) (Toh and Mizutani 1987). Cincindela larvae catch their prey by hiding near the entrance of a tunnel in the ground, while 
a

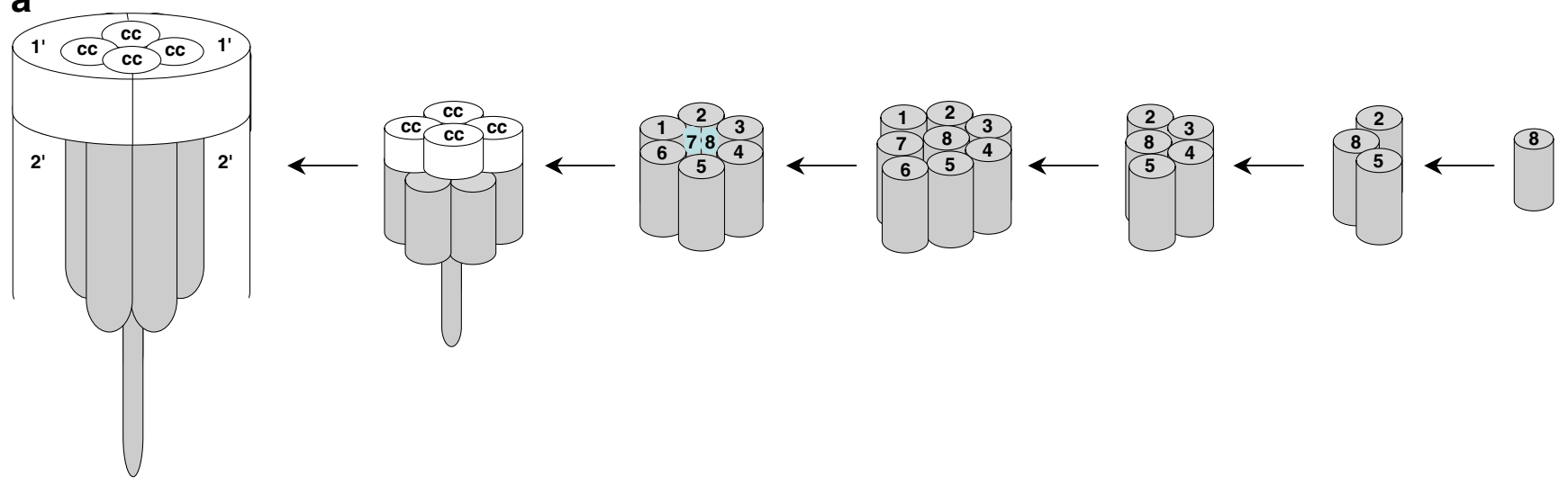

b
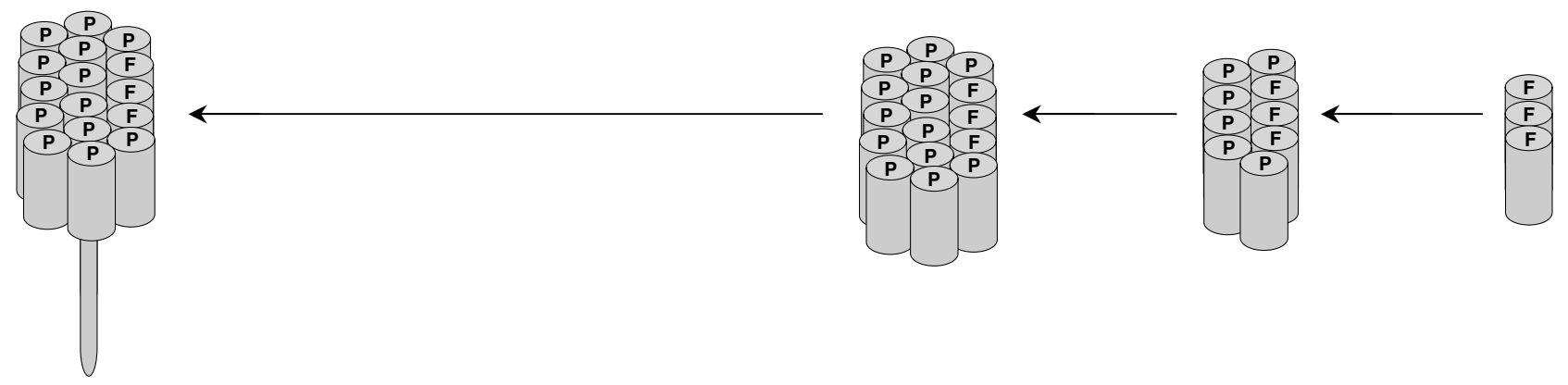

Fig. 8 Comparison of ommatidial differentiation in adult ommatidia and larval Bolwig organ of Drosophila. a Sequential specification of cell fates in the adult ommatidium. R8 photoreceptors express either long-wavelength opsin, or a blue-sensitive opsin. The peripheral photoreceptors 1-6 expressed a long-wavelength opsin. R7 photoreceptors express a UV-sensitive opsin. b Cell fate specification in the Drosophila Bolwig organ begins with three to four photoreceptors that will express the same blue-sensitive opsin that is expressed in a fraction of the R8 cells in the adult retina. These Bolwig organ cells

two well-developed stemmata monitor for approaching prey. When prey is detected, the larva jumps at it. Behavioral evidence suggests that binocular input from these stemmata is used to accurately estimate distance (Toh and Okamura 2001). Each of the large stemmata is characterized by a corneal lens and a single underlying layer of retinula cells, the photoreceptors. This sheet of retinula cells forms a cupshaped, extended retina comprising 4,000 to 5,000 cells in the two largest stemmata (Toh and Mizutani 1994a). Optical and physiological measurements show that these eyes are indeed image-forming (Mizutani and Toh 1995; Toh and Okamura 2007). This renders the overall functional organization of each stemma more similar to our eyes than to the adult insect compound eye. The importance of these structures is furthermore reflected by sophisticated larval neuropils (Toh and Mizutani 1994a, b). In addition, Cicindela stemmata also mediate escape behavior (Toh and Okamura 2001; Gilbert 1989).

Although detailed descriptions of the eyes of diving beetle larvae date back to 1889 (Patten 1888 on Acilus) and 1912 (Günther 1912 on Dytiscus), the complex organiza- are essential for the specification of the next cell fates and therefore referred to as founder $(F)$ cells similar to the adult R8 cells. The second type of Bolwig organ photoreceptors express a long-wavelength opsin and are referred to as peripheral $(P)$ photoreceptors. The Bolwig organ $\mathrm{P}$ photoreceptors are homologous to photoreceptors 1 , 2, 3 and 6 of the adult ommatidium. Note the lack of R7 and accessory photoreceptors in the Bolwig organ which is likely explained through precocious termination of cell fate specification compared to adult ommatidial development

tion of the larval eyes of Thermonectus marmoratus (Coleoptera: Dytiscidae) has only been approached recently. As is the case of Cincidela larvae, Thermonectus larvae are efficient predators. However, this aquatic larva feeds on small insects and other soft-bodied organisms while freely moving through the water. Within a single day, a first instar larva can eat up to ten nearly equally-sized mosquito larvae, and the much larger 3 rd instar larva can eat 40 or more (EKB, personal observation). The organization of the two largest stemmata on each side of the Thermonectus larval head differs strongly from "typical" eyes in that they have evolved into long tubular structures with several morphologically distinct retinas (Mandapaka et al. 2006) (Fig. 9c). Two morphological specializations of these eyes are at odds with most other eyes. First, instead of a single layer of retinula cells, light passes through a layered grating of photoreceptors that are oriented perpendicular to the direction of the light (distal retina), rather than in axis as in typical single-chamber eyes. Deeper in the eye there are receptor cells that are parallel to the direction of the light (proximal retina). The second unusual feature is that both retinas comprise narrow bands. 

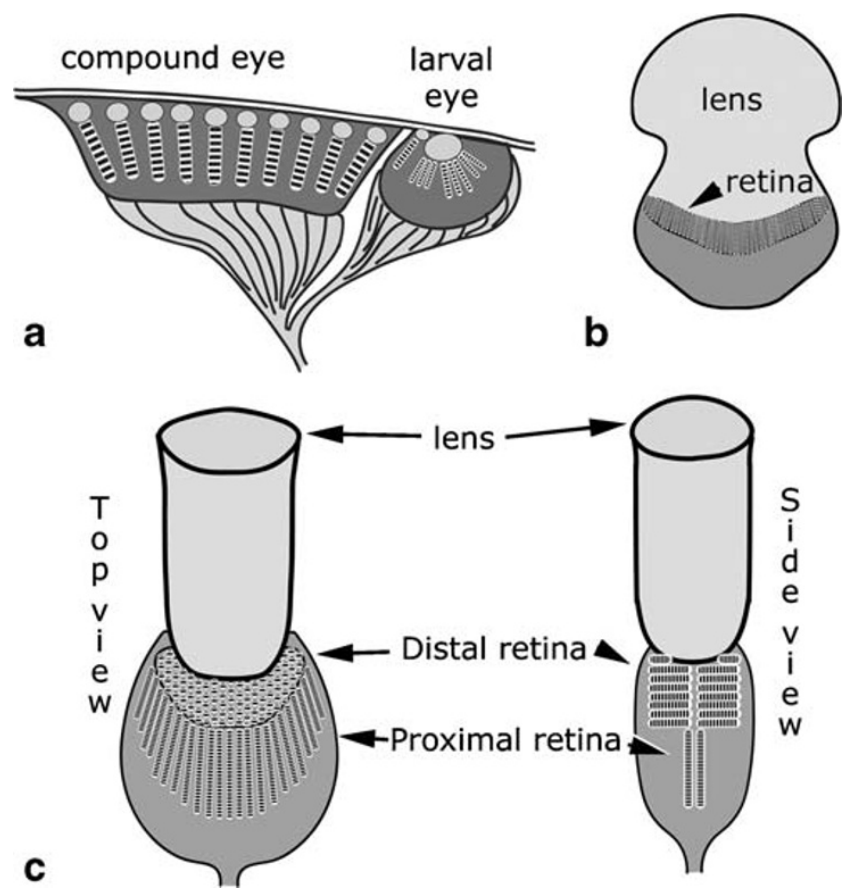

Fig. 9 a In mosquito larvae, the adult visual system develops early, enhancing the visual ability of larva and pupa; modified after (Gilbert 1994). b Among the most sophisticated larval visual systems is that of tiger beetles, in which some of the stemmata are image-forming camera-type eyes with thousands of receptor cells; modified after (Toh and Mizutani 1994a). c Larvae of the diving beetle Thermonectus marmoratus also have sophisticated eyes, the function of which is still unclear. At the base of some of their eyes, there are multiple layers of receptor cells, including cells that are perpendicular to the axis of incoming light (distal retina), as well as a narrow second retina (proximal retina)

While the function of the former organization still remains largely unclear, behavioral evidence suggests that the linear receptor organization is related to scanning movements that larvae perform prior to prey capture (Buschbeck et al. 2007). In some aspects, these eyes hence function not unlike a typical flat-bed scanner or copy machine; a visual mechanism that only has evolved a few times in animals (Land and Nilsson 2002). Thermonectus larvae are characterized by sophisticated optic neuropils as well.

\section{The Hofbauer-Buchner Eyelets: Larval Eyes Recycled}

For a long time, the final fate of the $\mathrm{BO}$ was as mysterious as their evolutionary origin. The first detailed studies of the changes in the Drosophila visual system during pupation suggested that the BOs underwent cell death and were altogether removed (Tix et al. 1989). Later investigations, however, showed this was only partially true. First, it was noted that the $\mathrm{BO}$ expressed the same opsin gene as the $\mathrm{H}-\mathrm{B}$ eyelets in the adult fly and had similar connectivity to second order neurons (Malpel et al. 2002). This key piece of evidence triggered a reassessment of what happens to the late BO and, specifically, if there was a link to the H-B eyelets. Following the fate of less than 16 neurons in the complex turnover of the central nervous system is a daunting (and whoever dissected a Drosophila pupa knows, messy) task. However, the use of a transgenic Drosophila line expressing a reporter gene in the $\mathrm{BO}$ has made it possible to bridge the gap and demonstrate that the $\mathrm{BO}$ "dedifferentiates" into the H-B eyelets of the adult fly (Helfrich-Forster et al. 2002). If this seems adventurous, one may note that this occurs while the BOs, a.k.a. H-B eyelets, travel from the outskirts of the larval head skeleton into the depth of the optic brain (Figs. 1 and 7). However, it must be noted that only four cells are maintained during this process (Helfrich-Forster et al. 2002). This implies the death of a considerable number of photoreceptors, explaining the previous conclusion that the $\mathrm{BO}$ experiences deconstruction (Tix et al. 1989).

The considerable developmental effort required to transform the BOs into the adult H-B eyelets suggests that these fulfill an important function in their new destination. Indeed, the H-B eyelets assist in the control of circadian activity patterns together with photoreceptors in the compound eye and ocelli (Helfrich-Forster et al. 2002; Veleri et al. 2007). In developmental terms, this function is carried over from the larval stage since the BOs also communicate with the circadian pacemaker system of the larva (Kaneko and Hall 2000). In evolutionary terms, the maintained circadian rhythm entrainment function of these organs is likely ancestral, considering that the entire retina of directly developing insects like crickets (Orthoptera, Gryllidae) functions as a light receptor for circadian rhythm entrainment (for review see Tomioka and Abdelsalam 2004). Nonetheless, it remains an interesting question to ask why the Drosophila larval eyes are recycled into supplementary extraretinal components of the circadian control system after relinquishing their visual orientation function.

Is Drosophila unique in recycling the larval eyes? Ironically, the bizarre repositioning of larval eyes into the brain had been documented much earlier in other endopterygote insects including lacewings, butterflies, and beetles (for recent review see Friedrich et al. 2006, Hariyama 2000). In these cases, the process is conspicuous because the larval photoreceptors continue to carry massive amounts of pigment serving as a natural reporter. Both the flour beetle $T$. castaneum and the diving beetle T. marmoratus are examples where the migration of the larval photoreceptors into the brain is well documented (Friedrich et al. 1996, 2006; Sbita et al. 2007). In the latter species, the larval portion of the adult eye remains quite large, although the majority of the larval eyes degenerate. Interestingly, in this species the underlying larval neuropils degenerate as well.

A systematic survey of the presence of homologous H-B eyelet brain photoreceptors has led to the conclusion that 
the presence of these specialized deep-brain visual organs can be used to discriminate endopterygote species from other insects (Friedrich et al. 2006). In conclusion, the differentiation of the larval photoreceptors to H-B eyelet-like organs during metamorphosis is a conserved trait of endopterygote insects. One may therefore assume that an important and universal evolutionary constraint precipitated for the preservation of circadian input functions in the adult.

\section{The Manifold Evolutionary Trajectories of Insect Eyes-Summary and Perspectives}

In this review, we have discussed some of the examples of how evolution has shaped a diversity of different insect eyes, despite the fact that the basic ommatidium is of ancient origin and includes a well-conserved set of cells. The evolution of specific visual capabilities has allowed many insects to successfully conquer specific niches. Some insects are particularly good at spatial resolution, whereas others are adapted for vision at low light levels. For other insects, vision lost some of its significance, resulting in the reduction of specific visual components. Many more examples are worth mentioning, such as dorsoventrally split eyes, sexually dimorphic eyes, or stalked eyes, to name a few (Hornstein et al. 2000; Hurley et al. 2002; Reifegerste and Moses 1999). Clearly, the total of insect eye diversity easily exceeds the scope of a single review and should be addressed in future work.

Recent advances in the field of comparative development ("evodevo") have added a new level of understanding to macro-evolutionary trajectories. For example, it is these kinds of data that allow us to understand the tight developmental connection between the stemmata of holometabolous larval and adult eyes. The recycling of larval photoreceptors into deep-brain circadian rhythm measurement devices further shows that different functions can be linked at the genetic level, with evolution acting upon any or all of these functions at the same time. The end result will be determined by overall fitness benefits, and any advantages from better eye performance must exceed any costs that arise from the new design. These include costs associated with matching sophisticated brain structures with sophisticated visual systems, pari passu. Considering again that only a few tips of many evolutionary icebergs in insect eye diversity could be addressed here, it becomes clear the insect eye holds promise for many discoveries of evolutionary versatility.

Acknowledgements We are grateful to T. Ryan Gregory for inviting us to contribute this review. Research in the Buschbeck lab has been funded by the National Science Foundation (IBN-0423963 and IOB0545978). Emily J. Woods, Niles Eldredge and the anonymous reviewer helped with comments on the manuscripts.

\section{References}

Beutel RG, Pohl H. Endopterygote systematics - where do we stand and what is the goal (Hexapoda, Arthropoda)? Syst Entomol 2006;31:202-19. doi:10.1111/j.1365-3113.2006.00341.x.

Bitsch C, Bitsch J. Evolution of eye structure and arthropod phylogeny. Crustac Issues 2005;16:185-214.

Bolwig N. Senses and sense organs of the anterior end of the house fly larvae. Vidensk Med Dansk Naturh Foren 1946;109:81-217.

Bonneton F, Brunet FG, Kathirithamby J, Laudet V. The rapid divergence of the ecdysone receptor is a synapomorphy for Mecopterida that clarifies the Strepsiptera problem. Insect Mol Biol 2006;15:351-62. doi:10.1111/j.1365-2583.2006.00654.x.

Briscoe AD, Chittka L. The evolution of color vision in insects. Annu Rev Entomol 2001;46:471-510. doi:10.1146/annurev.ento.46.1.471.

Buschbeck EK. The compound lens eye of Strepsiptera: morphological development of larvae and pupae. Arthropod Struct Dev 2005;34:315-26. doi:10.1016/j.asd.2005.04.002.

Buschbeck E, Ehmer B, Hoy R. Chunk versus point sampling: visual imaging in a small insect. Science 1999;286:1178-80. doi:10.1126/science.286.5442.1178.

Buschbeck EK, Ehmer B, Hoy RR. The unusual visual system of the Strepsiptera: external eye and neuropils. J Comp Physiol [A] 2003;189:617-30. doi:10.1007/s00359-003-0443-x.

Buschbeck EK, Sbita SJ, Morgan RC. Scanning behavior by larvae of the predacious diving beetle, Thermonectus marmoratus (Coleoptera: Dytiscidae) enlarges visual field prior to prey capture. J Comp Physiol a-Neuroethol Sens Neural Behav Physiol 2007;193:973-82.

Busto M, Iyengar B, Campos AR. Genetic dissection of behavior: modulation of locomotion by light in the Drosophila melanogaster larva requires genetically distinct visual system functions. J Neurosci 1999;19:3337-44.

Carroll SB. Endless forms most beautiful: the new science of evo devo and the making of the animal kingdom. Norton; 2005.

Champlin DT, Truman JW. Ecdysteroids govern two phases of eye development during metamorphosis of the moth Manduca sexta. Development 1998;125:2009-18.

Conde B, Pages J. Diplura. In: Naumann ID, Carne PB, Lawrence JF, Nielsen ES, Spradberry JP, et al, editors. The insects of Australia: a textbook for students and research workers. Melbourne: CSIRO, Melbourne University Press; 1991. p. 269-71.

Cook T, Desplan C. Photoreceptor subtype specification: from flies to humans. Semin Cell Dev Biol 2001;12:509-18. doi:10.1006/ scdb.2001.0275.

Cronin TW, Shashar N, Caldwell RL, Marshall J, Cheroske AG, et al. Polarization vision and its role in biological signaling. Integr Comp Biol 2003;43:549-58. doi:10.1093/icb/43.4.549.

Dickens JC, Eaton JL. External ocelli in Lepidoptera previously considered to be anocellate. Nature 1973;242:205-6. doi:10.1038/ $242205 \mathrm{a} 0$.

Dohle W. Are the insects terrestrial crustaceans? A discussion of some facts and arguments and the proposal of the proper name 'tetraconata' for the monophyletic unit Crustacea+Hexapoda. Ann Soc Entomol Fr NS 2001;37:85-104.

Dokucu ME, Zipursky SL, Cagan RL. Atonal, rough and the resolution of proneural clusters in the developing Drosophila retina. Development 1996;122:4139-47.

Egelhaaf A. Evidence for the priming role of the central retinula cell in ommatidium differentiation of Ephestia kuehniella. Rouxs Arch Dev Biol 1988;197:184-9. doi:10.1007/BF00427922.

Exner S. Die Physiologie der Facettierten Augen von Krebsen und Insekten. Wien: Franz Deuticke; 1891.

Fayers SR, Trewin NH. A hexapod from the early Devonian Windyfield Chert, Rhynie, Scotland. Palaeontology 2005;48:1117-30. 
Fischbach KF, Dittrich APM. The optic lobe of Drosophila melanogaster. 1. A Golgi analysis of wild-type structure. Cell Tissue Res 1989;258:441-75. doi:10.1007/BF00218858.

Freeman M. Cell determination strategies in the Drosophila eye. Development 1997;124:261-70.

Friedrich M. Evolution of insect eye development: first insights from fruit fly, grasshopper and flour beetle. Integr Comp Biol 2003;43:508-21. doi:10.1093/icb/43.4.508.

Friedrich M. Ancient mechanisms of visual sense organ development based on comparison of the gene networks controlling larval eye, ocellus, and compound eye specification in Drosophila. Arthropod Struct Dev 2006a;35:357-78. doi:10.1016/j.asd.2006.08.010.

Friedrich M. Continuity versus split and reconstitution: exploring the molecular developmental corollaries of insect eye primordium evolution. Dev Biol 2006b;299:310-29. doi:10.1016/j. ydbio.2006.08.027.

Friedrich M. Opsins and their regulation in the enigmatic Drosophila Bolwig organ: tricky lessons in homology inference. Bioessays 2008;30:980-93.

Friedrich M, Benzer S. Divergent decapentaplegic expression patterns in compound eye development and the evolution of insect metamorphosis. J Exp Zool 2000;288:39-55. doi:10.1002/ (SICI)1097-010X(20000415)288:1<39::AID-JEZ5>3.0.CO;2-T.

Friedrich M, Tautz D. Ribosomal DNA phylogeny of the major extant arthropod classes and the evolution of myriapods. Nature 1995;376:165-7. doi:10.1038/376165a0.

Friedrich M, Rambold I, Melzer RR. The early stages of ommatidial development in the flour beetle Tribolium castaneum (Coleoptera, Tenebrionidae). Dev Genes Evol 1996;206:136-46. doi:10.1007/s004270050039.

Friedrich M, Dong Y, Jackowska M. Insect interordinal relationships: insights from the visual system. Arthropod Syst Phylogeny 2006;64:133-48.

Gilbert C. Form and function of stemmata in larvae of holometabolous insects. Annu Rev Entomol 1994;39:323-49. doi:10.1146/annurev. en.39.010194.001543.

Gilbert C. Visual determinants of escape in tiger beetle larvae (Cicindelidae). J Insect Behav 1989;2:557-74. doi:10.1007/ BF01053354

Goodman LJ. Organisation and physiology of the insect dorsal ocellar system. In: Autrum H, editor. Comparative physiology and evolution of vision in invertebrates. Heidelberg: Springer; 1981. p. 201-86.

Greiner B, Ribi WA, Warrant EJ. Retinal and optical adaptations for nocturnal vision in the halictid bee Megalopta genalis. Cell Tissue Res 2004;316:377-90. doi:10.1007/s00441-004-0883-9.

Greiner B, Narendra A, Reid SF, Dacke M, Ribi WA, et al. Eye structure correlates with distinct foraging-bout timing in primitive ants. Curr Biol 2007;17:R879-80. doi:10.1016/j.cub.2007.08.015.

Grenacher H. Untersuchungen ueber das Sehorgan der Arthropoden, insbesondere der Spinnen, Insekten und Crustaceen. Gottingen: Vandenhoeck \& Ruprecht; 1879.

Günther K. Die Sehorgane der Larve und Imago von Dytiscus marginalis. Z Wiss Zool 1912;100:60-115.

Hafner GS, Tokarski TR. Morphogenesis and pattern formation in the retina of the crayfish Procambarus clarkii. Cell Tissue Res 1998;293:535-50. doi:10.1007/s004410051146.

Hariyama T. The brain as a photoreceptor: intracerebral ocelli in the firefly. Naturwissenschaften 2000;87:327-30. doi:10.1007/ s001140050732.

Harvey M, Shear W, Hoch H. Cavernicolous onychophora, arachnids, myriapods and insects. In: Wilkens $\mathrm{H}$, Culver DC, Humphreys WF, editors. Ecosystems of the world. Amsterdam: Elsevier; 2000. p. 79-94.

Harzsch S. The phylogenetic significance of crustacean optic neuropils and chiasmata: a re-examination. J Comp Neurol 2002;453:10-21. doi:10.1002/cne.10375.
Harzsch S, Vilpoux K, Blackburn DC, Platchetzki D, Brown NL, et al. Evolution of arthropod visual systems: development of the eyes and central visual pathways in the horseshoe crab Limulus polyphemus Linnaeus, 1758 (Chelicerata, Xiphosura). Dev Dyn 2006;235:2641-55. doi:10.1002/dvdy.20866.

Harzsch S, Melzer RR, Mueller CHG. Mechanisms of eye development and evolution of the arthropod visual system: the lateral eyes of myriapoda are not modified insect ommatidia. Org Divers Evol 2007;7:20-32. doi:10.1016/j.ode.2006.02.004.

Helfrich-Forster C, Edwards T, Yasuyama K, Wisotzki B, Schneuwly $\mathrm{S}$, et al. The extraretinal eyelet of Drosophila: development, ultrastructure, and putative circadian function. J Neurosci 2002;22:9255-66.

Hofbauer A, Buchner E. Does Drosophila have seven eyes? Naturwissenschaften 1989;76:335-6. doi:10.1007/BF00368438.

Hornstein EP, O'Carroll DC, Anderson JC, Laughlin SB. Sexual dimorphism matches photoreceptor performance to behavioural requirements. Proc R Soc Lond B Biol Sci 2000;267:2111-7. doi:10.1098/rspb.2000.12572007.

Horvath G, Varju D. Polarization pattern of freshwater habitats recorded by video polarimetry in red, green and blue spectral ranges and its relevance for water detection by aquatic insects. $\mathrm{J}$ Exp Biol 1997;200:1155-63.

Horváth G, Varjú D. Polarized light in animal vision: polarization patterns in nature. Berlin: Springer; 2004.

Hurley I, Pomiankowski A, Fowler K, Smith H. Fate map of the eyeantennal imaginal disc in the stalk-eyed fly Cyrtodiopsis dalmanni. Dev Genes Evol 2002;212:38-42. doi:10.1007/ s00427-001-0206-z.

Hwang UW, Kim W, Tautz D, Friedrich M. Molecular phylogenetics at the Felsenstein-zone: new approaches to the Strepsiptera problem using 5.8S and 28S rDNA sequences. Mol Phyl Evol 1998;9:470-80. doi:10.1006/mpev.1998.0518.

Hwang UW, Friedrich M, Tautz D, Park CJ, Kim W. Mitochondrial protein phylogeny joins myriapods with chelicerates. Nature 2001;413:154-7. doi:10.1038/35093090.

Imadate G. Protura. In: Naumann ID, Carne PB, Lawrence JF, Nielsen ES, Spradberry JP, et al, editors. The insects of Australia: a textbook for students and research workers. Melbourne: CSIRO, Melbourne University Press; 1991. p. 265-8.

Jacob F. Evolution and tinkering. Science 1977;196:1161-6. doi:10.1126/science.860134.

Kaneko M, Hall JC. Neuroanatomy of cells expressing clock genes in Drosophila: transgenic manipulation of the period and timeless genes to mark the perikarya of circadian pacemaker neurons and their projections. J Comp Neurol 2000;422:66-94. doi:10.1002/ (SICI)1096-9861(20000619)422:1<66::AID-CNE5>3.0.CO;2-2.

Kelber A. Invertrbrate color vision. In: Warrant E, Nilsson DE, editors. Invertebrate vision. Cambridge University Press; 2006. pp. 250-90.

Kelber A, Balkenius A, Warrant EJ. Scotopic colour vision in nocturnal hawkmoths. Nature 2002;419:922-5. doi:10.1038/ nature 01065 .

Kinzelbach RK. Morphologische Befunde an Fächerflüglern und ihre phylogenetische Bedeutung (Insecta: Strepsiptera). Zoologica 1971;41(119: 1. und 2. Hälfte):1-256.

Klingler M. Tribolium. Curr Biol 2004;14:R639-40. doi:10.1016/j. cub.2004.08.004.

Kral K. Spatial vision in the course of an insect's life. Brain Behav Evol 1998;52:1-6. doi:10.1159/000006547.

Kristensen NP. Phylogeny of extant hexapods. In: Naumann ID, Carne PB, Lawrence JF, Nielsen ES, Spradberry JP, et al, editors. The insects of Australia: a textbook for students and research workers. 2nd ed. Melbourne: CSIRO, Melbourne University Press; 1991. p. 125-40.

Kristensen N. Phylogeny of endopterygote insects, the most successful lineage of living organisms. Eur J Entomol 1999;96:237-53. 
Labhart T, Meyer EP. Detectors for polarized skylight in insects: a survey of ommatidial specializations in the dorsal rim area of the compound eye. Microsc Res Tech 1999;47:368-79. doi:10.1002/(SICI)10970029(19991215)47:6<368::AID-JEMT2>3.0.CO;2-Q.

Land MF. Optics and vision in invertebrates. In: Autrum $\mathrm{H}$, editor. Comparative physiology and evolution of vision in invertebrates, handbook of sensory physiology. Berlin: Springer; 1981. p. 471-592.

Land MF. The eye: optics. In: Kerkut A, Gilbert LI, editors. Comprehensive insect physiology, biochemistry and pharmacology. Oxford: Pergamon; 1984. p. 225-75.

Land MF. Optics of the eyes of the animal kingdom. In: Cronly-Dillon JR, Gregory RL, editors. Vision and visual dysfunction. Macmillan; 1991.

Land MF, Nilsson DE. In: Willmer P, Norman D, editors. Animal eyes. Oxford: Oxford University Press; 2002. 1-221 p.

Land MF, Gibson G, Horwood J, Zeil J. Fundamental differences in the optical structure of the eyes of nocturnal and diurnal mosquitoes. J Comp Physiol [A] 1999;185:91-103. doi:10.1007/s003590050369.

Laughlin SB. Energy as a constraint on the coding and processing of sensory information. Curr Opin Neurobiol 2001;11:475-80. doi:10.1016/S0959-4388(00)00237-3.

Laughlin SB, van Steveninck RRD, Anderson JC. The metabolic cost of neural information. Nat Neurosci 1998;1:36-41. doi:10.1038/236.

Liu Z, Friedrich M. The Tribolium homologue of glass and the evolution of insect larval eyes. Dev Biol 2004;269:36-54. doi:10.1016/j.ydbio.2004.01.012.

MacCarthy HR. Compund eye of male Stylops pacifica (Strepsiptera; Stylopidae). J Entomol Soc BC 1991;88:27-31.

Maksimovic S, Layne JE, Buschbeck EK. Behavioral evidence for within-eyelet resolution in twisted-winged insects (Strepsiptera). J Exp Biol 2007;210:2819-28. doi:10.1242/jeb.004697.

Malpel S, Klarsfeld A, Rouyer F. Larval optic nerve and adult extra-retinal photoreceptors sequentially associate with clock neurons during Drosophila brain development. Development 2002;129:1443-53.

Mandapaka K, Morgan RC, Buschbeck EK. Twenty eight retinas but only twelve eyes; an anatomical analysis of the larval visual system of the diving beetle Thermonectus marmoratus (Dytiscidae; Coleoptera). J Comp Neurol 2006;497:166-81. doi:10.1002/ cne.20974.

Marshall J, Cronin TW, Shashar N, Land M. Behavioural evidence for polarisation vision in stomatopods reveals a potential channel for communication. Curr Biol 1999;9:755-8. doi:10.1016/S09609822(99)80336-4.

Meinertzhagen IA. Evolution of the cellular organization of the arthropod compound eye and optic lobe. In: Cronly-Dillon JR, Gregory RL, editors. Vision and visual dysfunction. Boston: Macmillan; 1991. p. 341-62.

Melzer RR, Paulus HF. Evolutionswege zum Larvalauge der InsektenDie Stemmata der höheren Dipteren und ihre Abwandlung zum Bolwig-Organ. Z Zool Syst Evolutionsforsch 1989;27:200-45.

Melzer RR, Diersch R, Nicastro D, Smola U. Compound eye evolution: highly conserved retinula and cone cell patterns indicate a common origin of the insect and crustacean ommatidium. Naturwissenschaften 1997;84:542-4. doi:10.1007/s001140050442.

Melzer RR, Michalke C, Smola U. Walking on insect paths? Early ommatidial development in the compound eye of the ancestral crustacean, Triops cancriformis. Naturwissenschaften 2000;87:308-11. doi:10.1007/s001140050727.

Mizutani A, Toh Y. Optical and physiological-properties of the larval visual-system of the tiger beetle, Cicindela chinensis. J Comp Physiol [A] 1995;177:591-9. doi:10.1007/BF00207188.

Montell C, Jones K, Zuker C, Rubin G. A second opsin gene expressed in the ultraviolet-sensitive R7 photoreceptor cells of Drosophila melanogaster. J Neurosci 1987;7:1558-66.
Morante J, Desplan C, Celik A. Generating patterned arrays of photoreceptors. Curr Opin Genet Dev 2007;17:314-9. doi:10.1016/j. gde.2007.05.003.

Moses K. Drosophila visual system development. Berlin Heidelberg: Springer; 2002.

Nilsson DE. Optics and evolution of compound eyes. In: Stavenga DG, Hardie RC, editors. Facets of vision. Berlin: Springer; 1989. p. $30-73$.

Oakley TH. On homology of arthropod compound eyes. Integr Comp Biol 2003;43:522-30. doi:10.1093/icb/43.4.522.

Olberg RM, Seaman RC, Coats MI, Henry AF. Eye movements and target fixation during dragonfly prey-interception flights. J Comp Physiol a-Neuroethol Sens Neural Behav Physiol 2007;193:68593.

Osorio D, Bacon JP. A good eye for arthropod evolution. Bioessays 1994;16:419-24. doi:10.1002/bies.950160610.

Park T. Observations on the general biology of the flour beetle, Tribolium confusum. Q Rev Biol 1934;9:36-64. doi:10.1086/ 394454.

Patten W. Studies on the eyes of arthropods. II Eyes of Acilius. J Morphol 1888;2:97-190. doi:10.1002/jmor.1050020106.

Paulus HF. Die Feinstruktur der Stirnaugen einiger Collembolen (Insecta, Entognatha) und ihre Bedeuting fuer die Stammesgeschichte der Insekten. Z Zool Syst Evolut-forsch 1972;10:81-122.

Paulus HF. Eye structure and the monophyly of the Arthropoda. In: Gupta AP, editor. Arthropod phylogeny. New York: Reinhold; 1979. p. 299-371.

Paulus HF. Evolutionswege zum Larvalauge der Insekten - ein Modell für die Entstehung und die Ableitung der ozellären Lateralaugen der Myriapoda von Fazettenaugen. Zool Jb Syst. 1986;113:353-71.

Paulus HF. Das Homologisieren in der Feinstrukturforschung: Das Bolwig-Organ der hoeheren Dipteren und seine Homologisierung mit Stemmata und Ommatidien eines urspruenglichen Facettenauges der Mandibulata. Zoologische Beitrage N F 1989;32:437-78.

Paulus HF. Phylogeny of the Myriapoda-Crustacea-Insecta: a new attempt using photoreceptor structure. J Zoological Syst Evol Res 2000;38:189-208. doi:10.1046/j.1439-0469.2000.383152.x.

Pohl H. Phylogeny of the Strepsiptera based on morphological data of the first instar larvae. Zool Scr 2002;31:123-34. doi:10.1046/ j.0300-3256.2001.00078.x.

Ready DF, Hanson TE, Benzer S. Development of the Drosophila retina, a neurocrystalline lattice. Dev Biol 1976;53:217-40. doi:10.1016/0012-1606(76)90225-6.

Regier JC, Shultz JW, Kambic RE. Pancrustacean phylogeny: hexapods are terrestrial crustaceans and maxillopods are not monophyletic. Proc Biol Sci 2005;272:395-401. doi:10.1098/ rspb.2004.2917.

Reifegerste R, Moses K. Genetics of epithelial polarity and pattern in the Drosophila retina. Bioessays 1999;21:275-85. doi:10.1002/ (SICI)1521-1878(199904)21:4<275::AID-BIES3>3.0.CO;2-5.

Rösch P. Beiträge zur Kenntnis der Entwicklungsgeschichte der Strepsipteren. ZZeitschrift Naturwiss 1913;50:97-146.

Rossel S. Binocular stereopsis in an insect. Nature 1983;302:821-2. doi:10.1038/302821a0.

Sbita SJ, Morgan RC, Buschbeck EK. Eye and optic lobe metamorphosis in the sunburst diving beetle, Thermonectus marmoratus (Coleoptera: Dytiscidae). Arthropod Struct Dev 2007;37:449-62. doi:10.1016/j.asd.2007.08.003.

Schwind R. Polarization vision in water insects and insects living on a moist substrate. J Comp Physiol a-Sens Neural Behav Physiol 1991;169:531-40.

Sherk TE. Development of the compound eyes of dragonflies (Odonata) III. Adult compound eyes. J Exp Zool 1978;203:6180. doi:10.1002/jez.1402030107. 
Shultz JW, Regier JC. Phylogenetic analysis of arthropods using two nuclear protein-encoding genes supports a crustacean+hexapod clade. Proc R Soc Lond B Biol Sci 2000;267:1011-9. doi:10.1098/ rspb.2000.1104.

Sinakevitch I, Douglass JK, Scholtz G, Loesel R, Strausfeld NJ. Conserved and convergent organization in the optic lobes of insects and isopods, with reference to other crustacean taxa. J Comp Neurol 2003;467:150-72. doi:10.1002/cne.10925.

Smith GB, Watson JAL. Thysanura. In: Naumann ID, Carne PB, Lawrence JF, Nielsen ES, Spradberry JP, et al, editors. The insects of Australia: a textbook for students and research workers. Melbourne: CSIRO, Melbourne University Press; 1991. p. 275-8.

Sprecher SG, Pichaud F, Desplan C. Adult and larval photoreceptors use different mechanisms to specify the same Rhodopsin fates. Genes Dev 2007;21:2182-95. doi:10.1101/gad.1565407.

Stange G, Stowe S, Chahl JS, Massaro A. Anisotropic imaging in the dragonfly median ocellus: a matched filter for horizon detection. J Comp Physiol [A] 2002;188:455-67. doi:10.1007/s00359-0020317-7.

Steiner P. Studien and Panorpa communis. II. Zur Morphologie und postembryonalen Entwicklung des Kopfskeletts von Panorpa communis L. Z Morphol Oekol Tiere 1930;17:26-67. doi:10.1007/BF00406253.

Strausfeld NJ. Atlas of an insect brain. New York: Springer; 1976.

Strausfeld NJ. Crustacean-insect relationships: the use of brain characters to derive phylogeny amongst segmented invertebrates. Brain Behav Evol 1998;52:186-206. doi:10.1159/000006563.

Strausfeld NJ. The evolution of crustacean and insect optic lobes and the origins of chiasmata. Arthropod Struct Dev 2005;34:235-56. doi:10.1016/j.asd.2005.04.001.

Tix S, Minden JS, Technau GM. Pre-existing neuronal pathways in the developing optic lobes of Drosophila. Development 1989;105:739-46.

Toh Y, Mizutani A. Visual-system of the tiger beetle (Cicindela chinensis) larva. 1. Structure. Zoolog Sci 1987;4:974.

Toh Y, Mizutani A. Structure of the visual system of the larva of the tiger beetle (Cicindela chinensis). Cell Tissue Res 1994a;278:125-34.

Toh Y, Mizutani A. Neural organization of the lamina neuropil of the larva of the tiger beetle (Cicindela chinensis). Cell Tissue Res 1994b;278:135-44. doi:10.1007/BF00305785.

Toh Y, Okamura J. Behavioural responses of the tiger beetle larva to moving objects: role of binocular and monocular vision. J Exp Biol 2001;204:615-25.

Toh Y, Okamura JY. Morphological and optical properties of the corneal lens and retinal structure in the posterior large stemma of the tiger beetle larva. Vision Res 2007;47:1756-68. doi:10.1016/ j.visres.2007.02.023.

Tomioka K, Abdelsalam S. Circadian organization in hemimetabolous insects. Zoolog Sci 2004;21:1153-62. doi:10.2108/zsj.21.1153.
Trujillo-Cenoz O. The eye: development, structure and neural connections. In: Kerkut GA, Gilbert LI, editors. Comprehensive insect physiology, biochemistry and pharmacology. Oxford: Pergamon; 1985. p. 171-223.

Veleri S, Rieger D, Helfrich-Forster C, Stanewsky R. HofbauerBuchner eyelet affects circadian photosensitivity and coordinates TIM and PER expression in Drosophila clock neurons. J Biol Rhythms 2007;22:29-42. doi:10.1177/0748730406295754.

von Frisch K. Der Farbensinn und Formsinn der Biene. Zool Jahrb, Abt Allg Zool Physiol Tiere 1914;35:1-188.

von Frisch K. The dance language and orientation of bees. Cambridge, Mass.: Harvard University Press; 1967.

Walossek D, Muller KJ. Upper Cambrian stem-lineage crustaceans and their bearing upon the monophyletic origin of Crustacea and the position of Agnostus. Lethaia 1990;23:409-27. doi:10.1111/ j.1502-3931.1990.tb01373.x.

Warrant E. Invertebrate vision in dim light. In: Warrant E, Nilsson DE, editors. Invertebrate vision. UK: Cambridge University Press; 2006. p. 83-126.

Warrant EJ, Kelber A, Gislen A, Greiner B, Ribi W, et al. Nocturnal vision and landmark orientation in a tropical halictid bee. Curr Biol 2004;14:1309-18. doi:10.1016/j.cub.2004.07.057.

Warrant EJ, Kelber A, Wallen R, Wcislo WT. Ocellar optics in nocturnal and diurnal bees and wasps. Arthropod Struct Dev 2006;35:293-305. doi:10.1016/j.asd.2006.08.012.

Watson JAL, Smith GB. Archaeognatha. In: Naumann ID, Carne PB, Lawrence JF, Nielsen ES, Spradberry JP, et al, editors. The insects of Australia: a textbook for students and research workers. Melbourne: CSIRO, Melbourne University Press; 1991. p. 272-4.

Wehner R. Arthropods. In: Papi F, editor. Animal homing. London: Chapman and Hall; 1992. p. 45-144.

Wehner R, Labhart T. Polarisation vision. In: Warrant E, Nilsson DE, editors. Invertebrate vision. Cambridge University Press; 2006. pp. 291-348.

Willmann R. Phylogenetic relationships and evolution of insects. In: Cracraft J, Donoghue MJ, editors. Assembling the tree of life. New York: Oxford University Press; 2004. p. 330-44.

Wolff T, Ready D. Pattern formation in the Drosophila retina. In: Lawrence P, Martinez AM, editors. The development of Drosophila melanogaster. New York: Cold Spring Harbour Laboratory Press; 1993. p. 1277-326.

Yasuyama K, Meinertzhagen IA. Extraretinal photoreceptors at the compound eye's posterior margin in Drosophila melanogaster. J Comp Neurol 1999;412:193-202. doi:10.1002/(SICI)1096-9861 (19990920)412:2<193::AID-CNE1>3.0.CO;2-0.

Yoon CS, Hirosawa K, Suzuki E. Studies on the structure of ocellar photoreceptor cells of Drosophila melanogaster with special reference to subrhabdomeric cisternae. Cell Tissue Res 1996;284:77-85. doi:10.1007/s004410050568. 